\title{
Uncertainty communication in the environmental life cycle assessment (LCA) of carbon nanotubes (CNTs)
}

\section{S. Parsons*}

Centre for Environmental Strategy (CES),

University of Surrey,

Guildford, Surrey, UK

and

National Physical Laboratory (NPL),

Teddington, Middlesex, UK

Email: s.parsons@surrey.ac.uk

Email: sophie.parsons@npl.co.uk

${ }^{*}$ Corresponding author

\section{R.J. Murphy and J. Lee}

Centre for Environmental Strategy (CES),

University of Surrey,

Guildford, Surrey, UK

Email: rj.murphy@surrey.ac.uk

Email: j.lee@surrey.ac.uk

\section{G. Sims}

National Physical Laboratory (NPL),

Teddington, Middlesex, UK

Email: graham.sims@npl.co.uk

\begin{abstract}
Amidst the great technological progress being made in the field of nanotechnology, we are confronted by both conventional and novel environmental challenges and opportunities. Several gaps exist in the present state of knowledge or experience with nanomaterials. Understanding and managing the uncertainties that these gaps cause in LCAs is essential. Traditionally used for more established technology systems, environmental LCA is now being applied to nanomaterials by policy-makers, researchers and industry. However, the aleatory (variability) and epistemic (system process) uncertainties in LCAs of nanomaterials need to be handled correctly and communicated in the analysis. Otherwise, the results risk being misinterpreted, misguiding decision-making processes and could lead to significant detrimental effects for industry, research and policy-making. Here, we review current life cycle assessment literature for carbon nanotubes, and identify the key sources of uncertainty that need to be taken into consideration. These include: the potential for non-equivalency between mass and toxicity (potentially requiring inventory and impact models to be adjusted); the use of proxy data to bridge gaps in inventory data; and the often very wide ranges in material performance, process energy and product lifetimes quoted.
\end{abstract}


Keywords: life cycle assessment; LCA; life cycle assessment; uncertainty; carbon nanotubes; environmental impact; decision-making.

Reference to this paper should be made as follows: Parsons, S., Murphy, R.J. and Lee, J. and Sims, G. ( $\mathrm{xxxx}$ ) 'Uncertainty communication in the environmental life cycle assessment (LCA) of carbon nanotubes (CNTs)', Int. J. Nanotechnol., Vol. x, No. x, pp.xxx-xxx.

Biographical notes: Sophie Parsons is a Doctoral Research student at the University of Surrey and National Physical Laboratory (NPL), UK. Her research at NPL focuses on the environmental assessment of new and emerging materials. At the Centre for Environmental Strategy (CES), University of Surrey her doctoral work considers the wider aspects of sustainability and environmental policy. Her research mainly uses LCA methodology with a focus on producing guidance for the better inclusion of uncertainty in the LCA of emerging materials. Through improving how uncertainty is communicated, her work aims to make LCA more transparent, improving the way it is used by product designers and policy-makers to direct decisionmaking.

Richard J. Murphy is Professor of Life Cycle Assessment at the University of Surrey, Centre for Environmental Strategy. He has a BSc from King's College London and a PhD in Plant Sciences from Imperial College London. He has worked in the UK, New Zealand and The Netherlands and has advised the UK Climate Change Committee on LCA, was appointed in February 2013 to the Defra Hazardous Substances Advisory Committee and was invited to give evidence to the House of Lords Science \& Technology Select Committee enquiry into Waste Opportunities in November 2013.

Jacquetta Lee is a Senior Lecturer in the Centre for Environmental Strategy. Her main research interest is the development and application of life cycle thinking and sustainable systems analysis across a wide range of products and industries, including aerospace, automotive, construction and fast moving consumer goods. She is a member of the Aerospace, Defence, Security and Space working group on Design for Environment and sits on the Advisory Board for the Engineering Doctorate in Sustainable Engineering and Energy Systems at the University of Surrey.

Graham Sims is an NPL fellow (Composites and Materials Systems) and currently head of Science (Materials and Engineering). Graham leads the NPL international work on materials metrology, including co-chair of the VAMAS G15 pre-normalisation initiative and convenor for ISO working groups in composites and polymers standards. Graham is currently involved in CEN LCA standards development for nanomaterials, eco-design (EMIT consortium) and sustainable use of materials (BS 8905). He is a visiting Professor in the Faculty of Engineering and Physical Sciences of the University of Surrey.

This paper is a revised and expanded version of a paper entitled 'Uncertainty communication in the environmental life cycle assessment (LCA) of carbon nanotubes (CNTs)' presented at NANOTECH, Tunisia, 24-26 April, 2014. 


\section{Introduction}

Research and technical innovation has enabled the design of materials now vital to modern life and society. Understanding environmental life cycle aspects of these materials is becoming an essential perspective in the design process, with the introduction of the Eco-design Directive (2009/125/EC), and more recently the product environmental footprint (PEF). Environmental stewardship (the responsible use and protection of the natural environment) extends further than just a desire to protect the environment. Understanding the potential environmental impacts of new materials used in products can: reduce business risk, through anticipation of unforeseen and costly regulatory compliance; avoid damage to brand image; and can be used to analyse future supply security. Because of this, environmental analysis in the design stage is advisable. However, such early assessments are often prone to challenge due to low levels of practical experience, limited representative data from metrology, monitoring or surveillance and, in many cases, from the inherent novel properties of the materials themselves.

Carbon nanotubes (CNTs) are an emerging class of materials facing environmental scrutiny. CNTs have been relatively well documented in the risk, toxicity and life cycle literature when compared with other nanoparticles. Their small size, leading to large surface area, means toxicity is closely linked with size distribution, chemical composition and functionality. Parallels are often drawn with other ultrafine particulate matter $\left(\mathrm{PM}_{0.1}\right)$ as CNTs in their dispersed form fit this description. This has led to investigation over their potential toxicity and risk towards human health and the natural environment.

Assessing the environmental life cycle of a product containing CNTs has many uncertainties. These derive from missing data, lack of knowledge on scale-up of production to industrial levels, insufficient measurement of performance and lifetime of products, and the range in physio-chemical attributes that could affect toxicity. This means that currently life cycle assessment (LCA), commonly used to assess the life cycle of a product, cannot be properly applied to CNTs. LCA studies often do not include any consideration of the CNT itself, or if they do, impacts are considered speculatively. This is a major barrier to accurately presenting both the potential environmental issues and the environmental benefits of using CNTs in products.

A review of CNT LCA studies has been carried out by Upadhyayula et al. [1], which found that focus is needed on filling data gaps in the LCA of CNTs, along with showing the massive range in energy values for the production of CNTs. This is echoed by Hischier and Walser [2]. This has a large effect on the overall life cycle impacts attributed to CNT production. The modelling of CNT emissions to the environment has also been studied by several authors [3-5]. A better understanding of this is needed to inform risk and life cycle impact assessment. A three step-procedure has been recently suggested by Hischier [6] in order to identify impact relevant aspects in nanomaterial LCA including CNTs.

This paper describes the uncertainties in environmental assessment, and ranks them in terms of priority for reducing and managing them in LCAs. By doing this, a clear pathway towards developing better, more representative environmental assessments can be delivered. 


\section{LCA studies on carbon nanotubes: a review}

\subsection{Life cycle assessment and nanomaterials}

LCA for the environmental profiling of products and services has been standardised under ISO since 1997 (see ISO 14040: 2006). This technique for environmental systems analysis is now widely used to assess the potential environmental impacts a material might have over its whole 'cradle-to-grave' life cycle. In the last few years, there has been much discussion on the use of LCA to assess nanomaterials, with recognition of several key issues summarised below:

1 Differences in what drives toxicity. For bulk materials this is mass; however, for nanomaterials toxicity can potentially be more closely linked to particle size, shape, size distribution, functionality, etc. [7,8]. Furthermore, within the CNT family there is a wide range of size distribution, type and functionality. Since these characteristics have the potential to radically effect toxicity, modelling CNT toxicity cannot be generic and must be material specific [7,9].

2 Representation of material properties and performance. CNTs can be used for lightweighting, and its properties are dependent on functionalities such as particle size rather than mass. Uncertainties in performance of the product present key issues in modelling the life cycle as many assumptions need to be made $[8,10]$.

3 Limited availability of life cycle inventory (LCI) data. LCAs are data-driven and access to detailed process information, which is often proprietary and very difficult to obtain, is a key requirement. Lack of knowledge on emissions and accurate data on processing parameters inevitably introduce significant uncertainty. In the absence of direct industrial production and processing information, assumptions regarding scale-up are made $[2,7,8]$.

4 Lack of impact assessment data. Once the inventory data have been compiled, an assessment of the potential environmental impacts of those inputs and outputs should be performed. Due to a lack of well-defined environmental fate and exposure information, this assessment for nano-specific aspects is often speculative or cannot be performed $[2,7]$.

This present paper presents a three-level priority roadmap for the development of CNT LCA studies which includes all CNT-relevant considerations needed.

\subsection{Life cycle assessment of carbon nanotubes}

Thirteen studies assessing the life cycle of CNTs were reviewed [3,10-21]. Of these only four assessed the full life cycle $[3,10,16,19]$. Griffiths et al. [18] used a variety of thermodynamic and proxy data approaches to model data not found in the typical LCI databases. Most authors assessed only the production stage of CNTs [12-15,17,18]. Kushnir and Sanden [13] and Wender and Seager [21] found uncertainty in scaling up the process from laboratory to industrial scale. All the studies recognise energy demand in CNT production as the major contributor to environmental impact. Table 1 shows the range in energy demand values quoted for a number of different production methods of CNTs. 
Overall, none of the studies were able to represent CNT-specific impacts in their LCA. This was due to data gaps in both the life cycle inventory and the impact assessment. Major sources of uncertainty were in the modelling of scale up of the technology and the performance in its use phase [13,21]. As shown in Table 1, there is a very large range in quoted values for production energy for CNTs $(\mathrm{MJ} / \mathrm{kg}$ CNTs produced), even within the same process type. Uncertainty in the modelling scale-up from a laboratory process to a full-scale industrial process is found in yield calculation, energy demand and recycling of catalysts and solvents. Given the importance energy demand in CNT manufacture has (or is likely to have) on the overall life cycle environmental impact of CNT-containing products, understanding realistic demand per functional unit of product is crucial in producing representative CNT LCA studies.

Table 1 Range in energy values for CNT production by various synthesis routes

\begin{tabular}{lcl}
\hline Synthesis method & Energy (MJ/kg CNTs manufactured) & Reference \\
\hline Arc discharge & $3.2 \times 10^{5}$ & Healy et al. [17] \\
& $2.2 \times 10^{3}$ & Kushnir and Sanden [13] \\
CVD (VGCNF) & $1.1 \times 10^{4}$ & Khanna et al. [12] \\
CVD (floating bed) & $4.8 \times 10^{2}$ & Kushnir and Sanden [13] \\
HiPCO and CoMoCAT & $5.8 \times 10^{3}$ & Kushnir and Sanden [13] \\
& $1.6 \times 10^{5}$ & Healy et al. [17] \\
\hline
\end{tabular}

\subsection{Life cycle assessment of carbon nanotubes in carbon fibre sports equipment}

An LCA study was conducted in the present work to assess some of the claims made in the literature. The study chose a carbon fibre lacrosse stick shaft as the CNT-containing product, based on marketing literature from a carbon fibre pre-preg manufacturer. The scope of the study was the full life cycle of the product, excluding transport. The functional unit of the study was chosen as $400 \mathrm{~h}$ of training and match play. This was assumed to be the same as for an aluminium stick. Modelling bulk material and energy impacts only (no nano-specific consideration) the results of contribution analysis using selected environmental impact categories recommended in the International Reference Life Cycle Data System ILCD (Table 2) shows overwhelmingly that the major environmental impact occurs from CNT production related to energy demand by a CVD reactor process, assuming $828 \mathrm{MJ} / \mathrm{g}$ energy demand taken from Healy et al. [17]. However, realistic values to model CNT process energy requirements were very difficult to obtain, given the proprietary nature of the information. Similar to many of the studies reviewed, this meant that energy demand and processing assumptions were made on the basis of reviewing existing literature and by engaging with academics working within the area, but with little industrial input. Without engagement from the industry, process modelling will be restricted to values reflecting those at a laboratory scale with the risk that lower yields and higher energy demands may be assumed than is actually the case at scale. We recommend immediate cooperation between LCA practitioners and industry to better inform CNT LCAs. 
Table 2 Contribution analysis: different life cycle stages of a lacrosse stick containing CNTs

\begin{tabular}{|c|c|c|c|}
\hline \multirow[b]{2}{*}{ ILCD impact category } & \multicolumn{3}{|c|}{ Percentage (\%) contribution to total impact } \\
\hline & CNT production & $\begin{array}{c}\text { Sports } \\
\text { equipment } \\
\text { manufacture }\end{array}$ & $\begin{array}{l}\text { Incineration at } \\
\text { end-of-life }\end{array}$ \\
\hline $\begin{array}{l}\text { IPCC global warming, incl. biogenic carbon } \\
\text { [kg CO} \text { CO }_{2} \text {-Equiv.] }\end{array}$ & 94 & 5 & $<1$ \\
\hline $\begin{array}{l}\text { Resource depletion, fossil and mineral, reserve } \\
\text { base, CML2002 [kg Sb-Equiv.] }\end{array}$ & 98 & 2 & 0 \\
\hline $\begin{array}{l}\text { Ecotoxicity for aquatic fresh water, USEtox } \\
\text { (recommended) [CTUe] }\end{array}$ & 98 & 1 & $<1$ \\
\hline $\begin{array}{l}\text { Human toxicity cancer effects, USEtox } \\
\text { (recommended) [CTUh] }\end{array}$ & 99 & 1 & 0 \\
\hline $\begin{array}{l}\text { Human toxicity non-canc. effects, USEtox } \\
\text { (recommended) [CTUh] }\end{array}$ & 97 & 3 & 0 \\
\hline $\begin{array}{l}\text { Particulate matter/Respiratory inorganics, } \\
\text { RiskPoll [kg PM2,5-Equiv.] }\end{array}$ & 92 & 8 & 0 \\
\hline
\end{tabular}

\section{Identified areas of uncertainty}

Uncertainty in environmental assessment can be defined in a number of ways. It may be defined through either the nature or the location of the uncertainty. The nature of an uncertainty can be either aleatory or epistemic. Aleatory uncertainty represents inherent randomness shown by natural systems, i.e. something which cannot be reduced. Epistemic uncertainty comes from a lack of, or imperfection in, knowledge about a system of interest [22,23]. Generally in LCA, types of uncertainty and variability are distinguished by location. These are accepted as parameter, model, choices, temporal and spatial uncertainty [24]. For LCAs of CNTs these uncertainties are characterised in Table 3.

Table 3 Uncertainty characteristics for LCA of carbon nanotubes

\begin{tabular}{|c|c|}
\hline \multicolumn{2}{|c|}{ Type of uncertainty Source } \\
\hline Parameter & $\begin{array}{l}\text { Lack of and incomplete inventory data for nano-specific processes (including } \\
\text { CNT emissions, chemicals and catalysts used in those processes), as well as } \\
\text { characterisation factors at LCIA stage }\end{array}$ \\
\hline Model & $\begin{array}{l}\text { Imperfections in knowledge on nano-specific aspects; representation of nano- } \\
\text { properties, uncertainty in potential exposure and fate, scale-up of laboratory } \\
\text { scale processes, nanofunctionalities in use phase, modelling impacts in LCIA }\end{array}$ \\
\hline $\begin{array}{l}\text { Uncertainty in } \\
\text { choices }\end{array}$ & $\begin{array}{l}\text { Choices made to model technology scale-up, allocation procedures for } \\
\text { equipment used, production process (via CVD, HiPCO etc.) and end-of-life } \\
\text { management methods }\end{array}$ \\
\hline Temporal & $\begin{array}{l}\text { Primary/modelled data obtained for emissions averaged over the same time } \\
\text { periods, prospective assessment of scale up and future scenarios }\end{array}$ \\
\hline Spatial & $\begin{array}{l}\text { Relation of region/location specific data to actual production site emissions. } \\
\text { Modelling movement of CNTs between different environmental compartments, } \\
\text { and background concentrations of CNTs from natural or incidental sources } \\
\text { (e.g., combustion) }\end{array}$ \\
\hline
\end{tabular}




\section{Uncertainty levels in the LCA of CNT-containing products}

To achieve greater certainty in the results of LCAs of CNTs, the different sources of uncertainty need to be tackled (Figure 1). From the literature review and our LCA case study on a CNT-containing sports equipment, we consider that understanding realistic process parameters and life time performance through better engagement with industry and experts should be the first target for reducing uncertainty (particularly for the major factors of energy demand, ancillary materials and waste generation in CNT manufacture). Following this, improving fate models and toxicity assessments that best reflect environmental conditions is required to allow extension of the range of categories that can be adequately represented in the impact assessment phase of the LCA. Finally, inventory and impact assessment data can be continually improved to encompass a wider range of CNT variations (functionality, purity etc.) and CNT-containing products.

Figure 1 A roadmap for certainty improvement in the LCA of CNT containing product

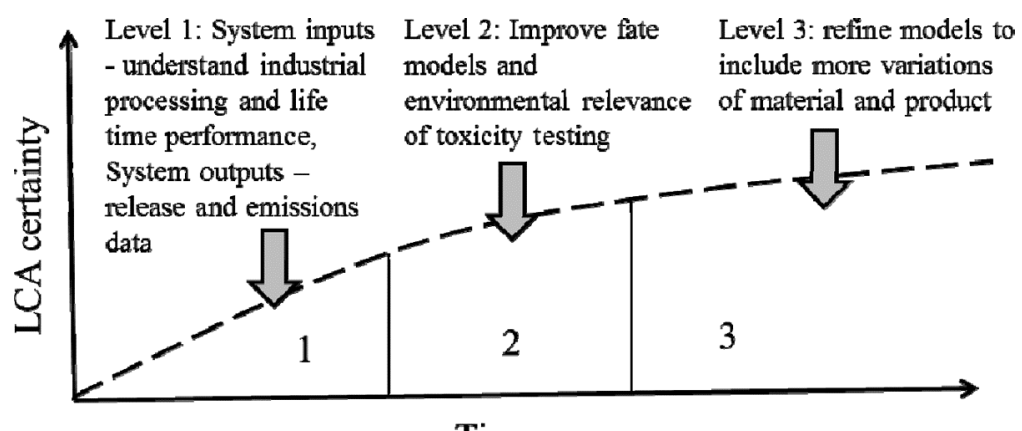

Time

Priority 1:

System input parameter, model and choice uncertainty in the life cycle inventory: Technology scale-up and processing throughout the life cycle. This also includes product performance information so that CNT-containing products can be compared against traditional technologies. Improving this parameter uncertainty will mean LCA studies are more representative of actual potential impacts rather than those based on speculative data. Here single-walled (SWCNTs) and multi-walled (MWCNTs) carbon nanotubes need to be distinguished.

System output parameter, model and choice uncertainty in the life cycle inventory: Improving data for release and emissions based on processing methods (CVD, HiPCO, CoMoCAT, etc.) understanding of release routes and likely methods for end- of-life processing.

\section{Priority 2:}

Parameter and model uncertainty in assessing impact: Improve fate models of CNTs in the environment, and toxicity assessment based on environmentally representative states of CNTs. Understanding this, coupled with findings in priority level 1 will lead to more representative emission/release values, from which impact assessment can be performed. 
Priority 3:

Continual improvement and refinement of life cycle inventory data: Given the diversity of CNT size distributions, purities, and functionalities, inventory information and impact assessment data will continually need to be updated to handle new products. Where SWCNTs and MWCNTs were distinguished in priority level 1, these datasets can now be updated to represent variations of each of these CNTs.

\section{Options to manage uncertainty in the short-term}

\subsection{Proxy or extrapolated data}

Surrogate data is often used where actual values do not exist in inventory databases. These can be scaled proxy values, direct proxy values, average proxy values or extrapolated values [25]. Where this may be possible for dealing with solvents or catalysts not included in databases, the differences between bulk carbon and CNTs make a surrogate data assumption very difficult. The levels of uncertainty around impacts when using surrogate data to represent CNTs should be made explicit in reporting LCA results.

\subsection{Data quality analysis and review of assumptions}

Data quality analysis can be done qualitatively or quantitatively through the use of tools such as pedigree matrices. The assumptions made in the model can be reviewed through engagements with experts and stakeholders.

\subsection{Sensitivity analysis}

Often used in LCA, sensitivity analysis using Monte Carlo is built in to many LCA software packages. It can be used to look at the effect changing input parameters has on the final LCA outcome. For it to be used effectively the practitioner should have an idea of likely ranges in input data. This may limit the value of sensitivity analysis with regard to CNT LCAs due to the inherent lack of knowledge; however, it could be applied where there is a range in quoted values e.g., for CNT production energy.

\subsection{Scenario analysis}

This technique is also often employed in LCA to examine how different modelling assumptions affect the final environmental impact results. This is potentially useful to assess uncertainties in CNT LCA, and has been used by other authors performing prospective analysis on nanomaterials [26].

\section{Summary and conclusions}

This review of uncertainty in the LCA of CNT-containing products has highlighted key issues and suggested a priority pathway for improving LCA certainty. None of the studies reviewed to date are able to account adequately for nano-specific impacts 
and few considered uncertainty per se. Identifying and prioritising uncertainties is clearly necessary to establish an appropriate LCA judgment on the environmental profiles of CNT products based on the current state of knowledge.

A range of issues need to be tackled in future research. These include; lack of inventory data for scaled-up production, differences between bulk and nanomaterial use phase functionality, and lack of impact assessment models and data for CNTs and nanomaterials in general, including differences in toxic action. This study has generated a prioritised list aimed at improving certainty in a stepwise approach targeted at achieving the biggest gains first. Priority 1: better engagement from industry on realistic scale-up approaches and industrial parameters to improve knowledge on system inputs over the whole life cycle. With CNT production being such an energy intensive process, it is important that energy demands properly representative of industrial practice are applied so that realistic LCA results can be obtained. Following this, output/emissions data is required, again through better engagement with industry and industrial experts to gain realistic release values. Priority 2: improvement of models for environmental risk assessment which are used to feed into the life cycle impact assessment phase of LCA. Priority 3: continuous improvement and database updates for CNTs. This goes beyond simple SWCNT and MWCNT differentiation to include ranges in size distribution, and surface functionality representative of the full diversity of CNTs.

In the meantime while these areas are being developed, various techniques must be used to manage and communicate uncertainty in current LCAs of CNTs. These techniques include the appropriate use and declaration of surrogate or proxy data, data quality analysis, and sensitivity and scenario analysis.

\section{Acknowledgements}

This work was supported by the National Physical Laboratory (NPL), Teddington, UK, and the Engineering and Physical Sciences Research Council (EPSRC). Research for this paper was carried out as part of an Engineering Doctorate in Sustainability for Engineering and Energy Systems in the Centre for Environmental Strategy, University of Surrey.

\section{References}

1 Upadhyayula, V., Upadhyayula, V., Meyer, D., Curran, M. and Gonzalez, M. (2012) 'Life cycle assessment as a tool to enhance the environmental performance of carbon nanotube products: a review', J. Cleaner Prod., Vol. 26, pp.37-47.

2 Hischier, R. and Walser, T. (2012) 'Life cycle assessment of engineered nanomaterials: state of the art and strategies to overcome existing gaps', Sci. Total Environ., Vol. 425, pp.271-282.

3 Kohler, A., Som, C., Helland, A. and Gottschalk, F. (2008) 'Studying the potential release of carbon nanotubes throughout the application life cycle', J. Cleaner Prod., Vol. 16, pp.927-937.

4 Nowack, B., David, R., Fissan, H., Morris, H., Shatkin, J., Stintz, M., Zepp, R. and Brouwer, D. (2013) 'Potential release scenarios for carbon nanotubes used in composites', Environ. Int., Vol. 59, pp.1-11. 
5 Gottschalk, F., Sonderer, T., Scholz, R. and Nowack, B. (2009) 'Modelled environmental concentrations of engineered nanomaterials $\left(\mathrm{TiO}_{2}, \mathrm{ZnO}, \mathrm{Ag}, \mathrm{CNT}\right.$, fullerene) for different regions', Environ. Sci. Techol., Vol. 43, No. 24, pp.9216-9222.

6 Hischier, R. (2014) 'Framework for LCI modelling of releases of manufactured nanomaterials along their life cycle', Int. J. Life Cycle Assess., Vol. 19, pp.838-849.

7 Gavankar, S., Suh, S. and Keller, A. (2012) 'Life cycle assessment at nanoscale: review and recommendations', Int. J. Life Cycle Assess., Vol. 17, pp.295-303.

8 Linkov, I. and Steevens, J. (2009) Nanomaterials: Risks and Benefits, Linkov, I. and Steevens, J. (Ed.), NATO Science for Peace and Security Series C: Environmental Security, Springer, Netherlands.

9 Som, C., Berges, M., Chaudhry, Q., Dusinska, M., Fernandes, T., Olsen, S. and Nowack, B. (2010) 'The importance of life cycle concepts for the development of safe nanoproducts', Toxicol., Vol. 269, pp.160-169.

10 Bauer, C., Buchgeister, J., Hischier, R., Poganietz, W., Schebek, L. and Warsen, J. (2008) 'Towards a framework for life cycle thinking in the assessment of nanotechnology', J. Cleaner Prod., Vol. 16, pp.910-926.

11 Khanna, V., Bakshi, B. and Lee, J.L. (2008) 'Assessing life cycle environmental implications of polymer nanocomposites', IEEE, Electronics and the Environment, pp.1-6.

12 Khanna, V., Bakshi, B. and Lee, L. (2008) 'Carbon nanofiber production: life cycle energy consumption and environmental impact', J. Ind. Ecol., Vol. 12, pp.394-410.

13 Kushnir, D. and Sanden, B. (2008) 'Energy requirements of carbon nanoparticle production', J. Ind. Ecol., Vol. 12, No. 3, pp.360-375.

14 Singh, A., Lou, H., Pike, R., Agboola, A., Li, X., Hopper, J. and Yaws, C. (2008) 'Environmental impact assessment of potential continuous processes for the production of carbon nanotubes', Am. J. Environ. Sci., Vol. 4, No. 5, pp.522-534.

15 Ganter, M., Seager, T., Christopher, M., Landi, B. and Raffaelle, R. (2008) 'A life cycle energy analysis of single wall carbon nanotubes produced through laser vaporisation', Sustainable Systems and Technology, 2009. ISSST'09. IEEE International Symposium, Pheonix AZ, pp.1-4.

16 Dahlben, L., Eckelman, M., Hakimian, A., Somu, S. and Isaacs, J. (2013) 'Environmental life cycle assessment of a carbon nanotube-enabled semiconductor device', Environ. Sci. Technol., Vol. 47, No. 15, pp.8471-8478.

17 Healy, M., Dahlben, L. and Isaacs, J. (2008) 'Environmental assessment of single-walled carbon nanotube processes', J. Ind. Ecol., Vol. 12, No. 3, pp.376-393.

18 Griffiths, O., O’Bryne, J., Torrente-Murciano, L., Jones, M. and Mattia, D. (2013) 'Identifying the largest environmental life cycle impacts during carbon nanotube synthesis via chemical vapour deposition', J. Cleaner Prod., Vol. 42, pp.180-189.

19 Chaudhry, Q., Aitken, R., Hankin, S., Donaldson, K., Olsen, S., Boxall, A., Kinloch, I. and Friedrichs, S. (2009) 'A lifecycle assessment study of the route and extent of human exposure via inhalation for commercially available products and applications containing carbon nanotubes', FERA, the Food and Environmental Research Agency, Final Project Report, CB0423.

20 Dahlben, L. and Isaacs, J. (2009) 'Environmental assessment of manufacturing with carbon nanotubes', IEEE, pp.1-6.

21 Wender, B. and Seager, T. (2011) 'Towards prospective life cycle assessment: single wall carbon nanotubes for lithium-ion batteries', IEEE, Sustainable Systems and Technology, pp.1-4.

22 Skinner, D., Rocks, S. and Pollard, S. (2013) 'A review of uncertainty in environmental risk: characterising potential natures, locations and levels', J. Risk Res., Vol. 17, No. 2, pp.195-219.

23 Bedford, T. and Cooke, R. (2001) Probabilistic Risk Analysis: Foundations and Methods, Cambridge University Press, Cambridge, UK. 
24 Huijbregts, M.A.J. (2002) 'Uncertainty and Variability in environmental life cycle assessment', Int. J. Life Cycle Assess., Vol. 7, No. 3, p.173.

25 Mila i Canals, L., Azapagic, A., Doka, G., Jefferies, D., King, H., Mutel, C., Nemecek, T., Roches, A., Sim, S., Stichnothe, H., Thoma, G. and Williams, A. (2011) 'Approaches for addressing life cycle assessment data gaps for bio-based products', J. Ind. Ecol., Vol. 15, No. 5 , pp.707-725.

26 Walser, T. (2011) 'Prospective environmental life cycle assessment of nanosilver T-shirts', Environ. Sci. Technol., Vol. 45, pp.4570-4578. 